\title{
Research on the Innovation of Media Marketing under the Upsurge of Webcast
}

\author{
Feng Jujun \\ Xi'an Peihua University, Xi'an, Shaanxi, 710125
}

Keywords: webcast; media marketing; marketing model; innovation and development

\begin{abstract}
At present, as a novel form of programming, webcasting has created an upsurge in the entire population because of its diversity of content and flexibility. This paper analyzes the current status of webcast media marketing models, as well as the characteristics, content and marketing models of marketing, analyzes the advantages of webcast marketing models under the Internet to other media marketing methods, and analyzes the media industry's business with webcast economy as an example. In view of issues such as it is difficult to maintain the enthusiasm of the user and malicious marketing that are faced by current webcast marketing, development suggestions have been put forward in terms of analysis of webcast marketing strategies and innovations in webcast marketing development.
\end{abstract}

\section{Introduction}

With the great development of information technology and the popularization of Internet, the development of Internet provides a great advantage to the new economy of media industry. Being different from the increasing development that webcast of the traditional media boasts depending on the advantage of Internet, various limits of the transmission of information and perspective of the traditional media have been broken by the development of Internet. Thus, webcast emerges at the right moment with the growth of new media and is forming the scale gradually. Webcast boasts it great power and rich content because of its compositionality, full member, no boundary limit, interactivity and diversity, which may provide more ways of interpretation and sometimes even surpass the immediacy of traditional media. The paper herein will lay emphasis on the discussion of the effect and change that webcast will bring to marketing pattern.

\section{Background of the Upsurge of Webcast}

With the great development of Internet and mobile Internet and the increasing improvement of information communication technology, new media is rewarded with the growth of mobile social network, which may change the way of receiving information of people at the same time.

Mentioning the audience preference, on one hand, the atmosphere of the Internet is open and diversified. People may prefer to choose an entertaining way to communicate in a virtual network. Moreover, with the significant convenience of the one-click propagation of fragmented information, people prefer to cater to the mass entertainment trend to trigger the circus-see.

On the other hand, mentioning the technology, the Internet has transmitted from web portals to mobile social network. And Sina Weibo hasn't monopolized the social platform, with the new upsurge of short video, social platform has already remodeled the way of people's expressing and communicating.

It's not long time since the webcast platform upsurges and there has been no official definition yet. From a narrow point of view, webcast is an emerging video entertainment with high interactivity, which means the host may usually sing songs or play games on the Internet webcast platform through video recording tools and audience can interact with the host through bullet screen and reward the host with virtual property.

With the richer and richer content and form of webcast and higher and higher the marginal benefit brought by it, people has been getting used to chatting with others, learning makeup, interacting with idols and getting information of products through webcast platform. Being different 
from WeChat and Weibo that communicate through words and pictures, webcast may connect people through intuitive video and it has become the new platform and space of Internet communication.

\section{Effect of Webcast on Media Marketing}

The core of webcast economy is the new economy that may transfer the number of fans to the power of purchasing and consumption. The large group of fans will be oriented as clients by brands through data analysis, which may lead to the transformation of the commercial cash from fans and network flow to benefits. With full involvement of webcast of people, webcast marketing model which is the webcast economy attracting people through content and pan entertainment has a great impact on the traditional marketing model.

\subsection{Transformation from entity channel to Internet}

After being popular of webcast, the imaginary of value space may depend on two indicators, one is the propagation and the other is its impression. Propagation means the attribute of channel of the host, which refers to how many people the host can attract in the cyber world. On the other side, impression means whether the information that the host expresses can be trusted by fans and become hot topic on the Internet discussed by cyber citizens. The nature of webcast is the famous ID of the self-media. The content and performance on the Internet will bring attention to the hosts themselves and the benefit of the commercial chain are all realized through the Internet. Since in the specific field, the expertise of web stars may help themselves orient the needs of fans and finally improve the conversion rate of consumption.

\subsection{Resource link turns to content link}

Traditional marketing depends on companies to link both material production and interpersonal connections and then distribute and link resources, finally sell through physical stores. It is the company that the traditional marketing relies on to organize and distribute resources. While webcast economy is to ignite the social network through the content and link the audience with words, pictures, voices and videos. It orients areas of tourism, constellation, cate and so on. Hosts will share their strategies, ideas and thoughts with oriented fans and realize the precise focus of products. Finally hosts can achieve the sales of products after fans accept the guidance of products. So, webcast economy is triggered and linked by content, differing from the traditional mode that stars help increase exposure of products to win the benefits, which means hosts may bring not only the brand but also the channel themselves and produce the content at the same time. They set connections between fans and content directly through the platform.

\subsection{Turning humanity planning to spontaneous marketing}

Brand exists as the form of organization as company in the traditional economic mode, which differs from the spontaneous spread of Internet. If the company wants to form scale, it has to collect various kinds of resources offline and rely on the construction of traditional media. But what can't be ignored is that the system of organization may be too complicated and rely too much on human connections, or even the connections of resources, which all will increase the cost of the construction of brand. With the increasing growth of Internet, social network may link everything and at the same the attractive marketing contributed to webcast reflects that fans chase the brands spontaneously and shows the admiration of fans to hosts, which is an act of spontaneous marketing.

\section{Problems in Webcast Marketing}

Webcast marketing, as the outcome of the Internet, has been overturning the traditional marketing mode while it also triggers some problems with the gradual improvement. 


\subsection{Hard to maintain the passion of clients.}

It is hard to maintain the heat of the network for webcast marketing. With the increasing development of the Internet and social platform, maintaining the heat refers to two sides. On one side, it is not easy to provide qualified content continuously, which may not meet the needs of fans from both the quality of content and the frequency of updating. On the other hand, serious copy and imitation may make fans tired of webcast marketing, which may lead to the loss of fans and network focus. This may be the dilemma that webcast marketing may face.

\subsection{Malicious marketing.}

Currently there are so many webcast platforms, while some of them lack of standardization. Some problems of malicious marketing happen in some of platforms. And they can't be solved thoroughly because of the difficulty of supervision.

\section{Advice on the Development of Webcast Marketing}

\subsection{Develop multiple platforms.}

Development on multiple platforms at the same time may conquer the disadvantage of relying too much on single platform and decrease the heavy dependency on certain platform, which will also benefit the cooperation among platforms and win both recommendation and support.

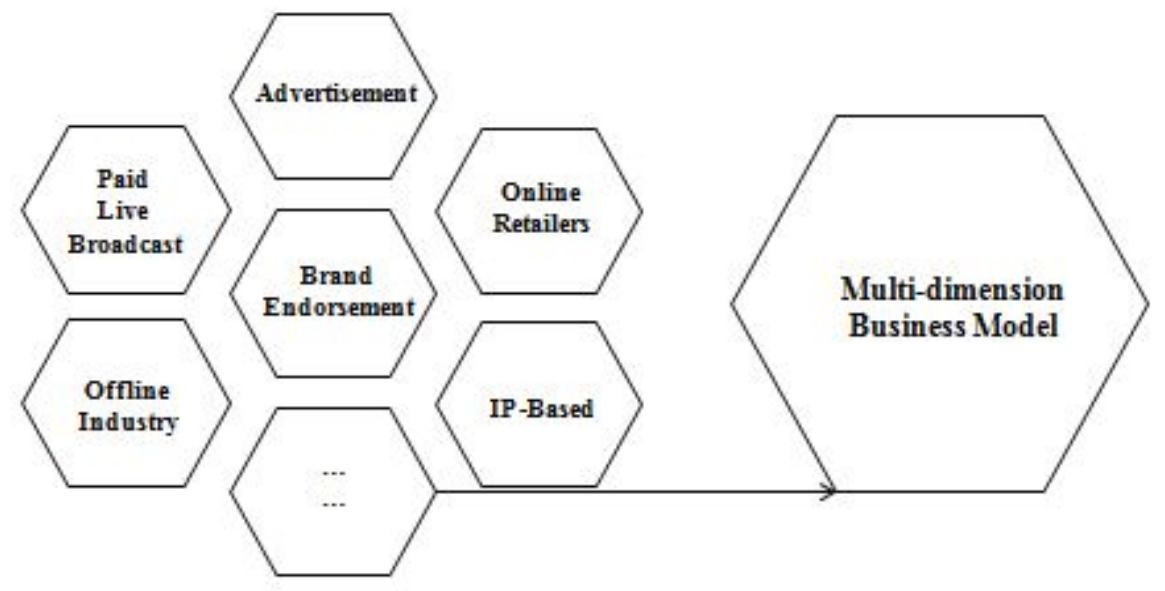

Fig.1 Multiple profit models

\subsection{Resist the vulgar and strengthen supervision.}

The strong effect webcast boasts emphasizes its social responsibility as a part of media, so its content should be restraint by regulations and strictly supervised.

\section{Conclusion}

The Internet has been driving the change and innovation of traditional industries. The emergence of webcast economy and the webcast marketing brought by it is actually the outcome of people's new entertainment habits, new channels of communication and new innovative content. And with the increasing growth and popularization of mobile Internet technology, there will be more and more original webcast content emerging on the Internet and webcast economy will be pushed to a higher level by capital investment. For the long run, webcast marketing, as a new mode, will split from the inside and form into a stable economic structure based on different modes of the realization of cash. Moreover, industrial chains deriving from webcast economy will be stronger and stronger. 


\section{References}

[1] Zhang Fen. The user's psychology and demand analysis in the era of new media [J]. Shan Hai Jing, 2016(6).

[2] Lin Xiang. Research on Media Economy Development in the Internet Age-Based on Platform Economic Theory [M]. Wuhan: Wuhan University, 2013.

[3] Xie Tao, Wang Xiaohong. Strategies and Thoughts on Multi-screen Live Streaming of TV Media: Taking the Live Broadcast Practice of Some TV Media as an Example [J]. Young Journalist, 2016(34):16-18.

[4] Zhang Hongfei, Li Ning. The Six Business Models of Media [J]. Editorial Friends, 2015(12): 41-45.

[5] Luo Yi, Li Liangyu. Business Model Innovation in the Internet Age: A Perspective of Value Creation [J]. China Industrial Economy, 2015(1): 95-107. 